\title{
Effect On The Processing Characteristics Of ZnO Varistors Produced Using Vibratory Milling
}

\author{
Maura Kelleher \\ Technological University Dublin, maura.kelleher@tudublin.ie \\ M.S.J. Hashmi \\ Dublin City University, saleem.hashmi@dcu.ie
}

Follow this and additional works at: https://arrow.tudublin.ie/engmecdesignconf

Part of the Ceramic Materials Commons, and the Semiconductor and Optical Materials Commons

\section{Recommended Citation}

Kelleher, M.C., Hashmi, M.S.J., Effect on the processing characteristics of $\mathrm{ZnO}$ varistors produced using vibratory milling, AIP Conference Proceedings Volume 1315, 2010, Pages 253-258 International Conference on Advances in Materials and Processing Technologies, AMPT2010; Paris; France; 24 October 2010 through 27 October 2010 doi:10.21427/nqnq-0904

This Conference Paper is brought to you for free and open access by the School of Mechanical and Design Engineering (old) at ARROW@TU Dublin. It has been accepted for inclusion in Conference Papers by an authorized administrator of ARROW@TU Dublin. For more information, please contact arrow.admin@tudublin.ie, aisling.coyne@tudublin.ie,gerard.connolly@tudublin.ie.

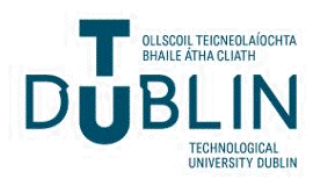




\title{
Effect On The Processing Characteristics Of ZnO Varistors Produced Using Vibratory Milling
}

\author{
M.C. Kelleher ${ }^{\mathrm{a}}$ and M.S.J. Hashmi ${ }^{\mathrm{b}}$ \\ ${ }^{a}$ School of Manufacturing and Design Engineering, Dublin Institute of Technology, Bolton St., Dublin 1, Ireland. \\ Email: Maura.Kelleher@dit.ie \\ ${ }^{b}$ School of Mechanical Engineering, Dublin City University, Glasnevin, Dublin 9, Ireland. Email: \\ Saleem.Hashmi@dcu.ie
}

\begin{abstract}
Each manufacturing stage in the production of zinc oxide varistors from powder preparation to the final encapsulated device is important not only for the formation of the varistor component with optimum microstructure and thus electrical characteristics but also for avoiding the introduction of flaws and reduced yield. In this paper the authors describe and discuss the effect of multi-elemental oxide additives having been milled for different durations using a vibratory mill with cylindrical zirconia media on the powder characteristics of the subsequent processing stages. A commercial $\mathrm{ZnO}$ varistor formulation was used. The subsequent processing stages that are given particular attention include first spray drying and second milling. The characteristics include agglomerate size, powder density and elemental uniformity of the first spraydried powders, and particle size, specific surface area, zirconium concentration and pore size of the second milled powders. They were evaluated using laser diffraction, scanning electron microscopic, mercury porosimetry, Brunauer, Emmett and Teller (BET) and inductively coupled plasma (ICP) analysis. Some interesting correlations are observed between the powder properties and vibratory milling durations of the mixed metal oxide additives (MMOA).
\end{abstract}

Keywords: $\mathrm{ZnO}$ varistors, Vibratory milling, Powder characteristics, Zirconium concentration.

PACS: $81,81.20 \mathrm{Ev}, 82.80 \mathrm{Dx}, 83.50 \mathrm{xa}, 83.80 \mathrm{Fg}$.

\section{INTRODUCTION}

Handling of fine, usually sub-micrometer and/or nanometer sized, powders in large quantities require a high degree of process control to achieve the desired microstructural characteristics ${ }^{1}$. The desired microstructural characteristics include small defect size, narrow distribution in grain size, well-dispersed secondary phases and homogeneous composition of all phases present. The processing of $\mathrm{ZnO}$ varistors from powders is no different.

$\mathrm{ZnO}$ varistors, first discovered by Matsuoka ${ }^{2}$ are semiconductor ceramic devices exhibiting high non-linear current-voltage characteristics ${ }^{3,4}$. Each electrical characteristic is highly reliant on the composition and the atomic, nano-, micro- and macrostructural characteristics, which are in turn highly reliant on each processing stage from powders to final device. Inhomogeneous microstructure can cause a large spread in current-voltage characteristics ${ }^{4,5}$. Control of the microstructure is required to obtain maximum varistor performance.

Novel powder processing methods investigated to control the microstructure include chemically derived mixed metal oxides ${ }^{6}$, incorporation of $\mathrm{ZnO}$ seeds ${ }^{7}$, prior preparation of secondary phases ${ }^{8}$ and mechanical milling. Some of these methods have not been widely implemented on an industrial scale, possibly due to high manufacturing costs and low reproducibility. The endeavour to obtain maximum homogeneity and narrow grain size by using highly mixed powders on atomic and nanometer scales may not be sufficient. Some variables used in the conventional processing of varistor powders, which have their own effect on the microstuctural and electrical properties, may have been over looked. One such variable may be 
the concentration of elements introduced indirectly as a result of media wear during milling. A previous publication by Kelleher et al. (2008) showed that zirconium was present in the metal oxide additive powders in the parts per million ( $\mathrm{ppm}$ ) concentration levels as a result of vibratory milling. Knowledge of the effect of zirconium concentration on the electrical properties of $\mathrm{ZnO}$ varistors is scarce. More knowledge is required on the influence of milling on the subsequent processing, microstructural and electrical characteristics of $\mathrm{ZnO}$ varistors.

In this study the preparation of high voltage varistor powders ready for compaction and sintering involved a number of processing stages. These stages were conducted on a pilot scale. Mixed metal oxide additives (MMOA) were milled using a vibratory mill with cylindrical $\mathrm{ZrO}_{2}$ media in the first milling stage for different durations. The effect of different milling durations on the powder properties of the first milling stage was reported ${ }^{10}$. This study focuses on the effect of different milling durations on the powder characteristics of the subsequent processing stages, second spray drying and second milling.

\section{EXPERIMENTAL PROCEDURE}

\section{Reagents}

The metal oxide additives of a commercial high voltage $\mathrm{ZnO}$ arrester formulation were used; $\mathrm{Bi}_{2} \mathrm{O}_{3} 0.5$ mol.\%, $\mathrm{Sb}_{2} \mathrm{O}_{3} 1.0$ mol.\%, $\mathrm{MnO}_{2} 0.5$ mol.\%, $\mathrm{Co}_{3} \mathrm{O}_{4} 1.0 \mathrm{~mol} . \%$, NiO $0.5 \mathrm{~mol} \%$ and $\mathrm{SnO}_{2} 0.5 \mathrm{~mol} . \%$. These are collectively referred to as mixed metal oxide additives (MMOA). $\mathrm{ZnO}, 96.0 \mathrm{~mol} \%$, is the main constituent of the varistor formulation.

\section{Process Stages and Equipment}

The stages used for the preparation of $\mathrm{ZnO}$ varistor powders ready for compaction included first milling, first spray drying, calcining, second milling and second spray drying. Six batches of MMOA were prepared using a vibratory mill for durations of $0,1,3,6,12$ and 18 hours in random order. This stage, called first milling, was carried out using a vertical mill (Sweeco Ind., model M-18) and has been described earlier by the authors ${ }^{10}$.

Each batch of MMOA was shear mixed with the main constituent $\mathrm{ZnO}$, binder and lubricant for one hour to form six slurries ready for drying. Drying was achieved using a spray dryer (Bowen Engineering Ind., model No.1). This is called the first spray drying stage. Samples were taken from each batch of spray-dried powder and examined for agglomerate size, elemental homogeneity, bulk and tap density. Calcination was carried out using a pilot kiln.

The six batches of calcined $\mathrm{ZnO}$ varistor powders were then individually milled using the vibratory mill (M-18) for a standard time of 6 hours in random order. This is called the second milling stage. Each batch used $5 \mathrm{~kg}$ of powder with 5 litres of deionized water. Samples of the flowing slurry were taken from the mill at the end of each milling operation and examined for particle size, specific surface area, pore size and zirconium concentration.

\section{Analytical Instruments}

The bulk density was determined when the powder was poured without agitation into a 100 $\mathrm{ml}$ graduated cylinder. The tap density was determined by tapping a graduated cylinder containing $100 \mathrm{ml}$ of powder 1,000 times with a Quantachrome tapping machine. Scanning Electron Microscopic studies of the elemental homogeneity was determined using a Zeiss FESEM operating at $20 \mathrm{kV}$. Agglomerate size and distribution was determined with a Malvern MasterSizer Laser Diffractometer with dry state conditions. The distribution in size at 10,50 and 90 cumulative percent is denoted as D10, D50 and D90, respectively. The specific surface area, 
particle size, pore size and $\mathrm{Zr}$ concentration were determined by Brunauer, Emmett and Teller (BET), laser diffractometry, mercury porosimetry and inductively coupled plasma (ICP) analysis respectively. These techniques have been described previously by the authors ${ }^{10}$.

\section{RESULTS AND DISCUSSION}

\section{Characteristics of The First Spray Dried Powders}

The influence of vibratory milling duration of the MMOA on the powder density, agglomerate size and elemental homogeneity of the first spray-dried powders was studied. Some characteristics were influenced by the duration of vibratory milling whereas others were not. The density of the first spray-dried powders (Fig. 1) increased slightly, whereas the average and range of agglomerate size (Fig. 2) were unaffected with increasing duration of vibratory milling of the MMOA.

The slight increase in powder density with increasing milling duration of the MMOA appears to correspond with the reduction in size and distribution of the MMOA ${ }^{10}$. The reduction in size and distribution of the MMOA may have resulted in reduced friction between the spray-dried agglomerates causing them to flow easier and move closer together.

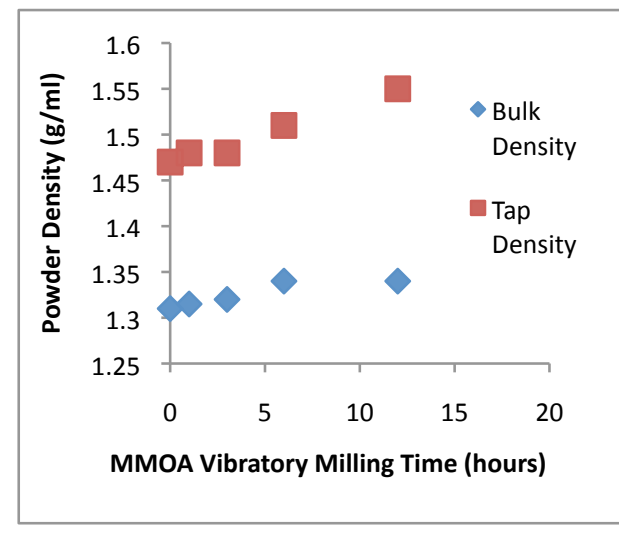

FIGURE 1. Effect of vibratory milling time of the MMOA on the bulk and tap density of the first spray-dried powders.

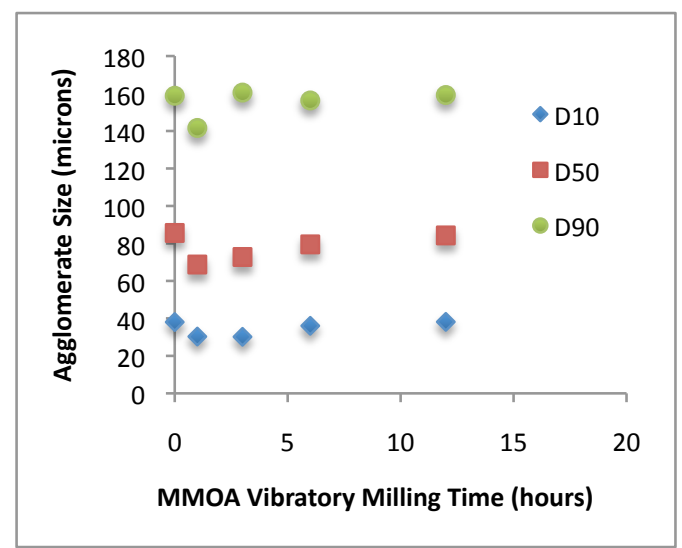

FIGURE 2. Effect of vibratory milling time of the MMOA on the agglomerate size of the first spraydried powders.

Back scattering electron microscopic and elemental analysis (Fig. 3) illustrates that the level of metal oxide uniformity is strongly influenced by the duration of MMOA milling. The grey, bright grey and white areas correspond with the metal oxide particles of lowest ( $\mathrm{Mn}, \mathrm{Co}, \mathrm{Ni}$ and $\mathrm{Zn}$ ), medium ( $\mathrm{Sn}$ and $\mathrm{Sb}$ ), and highest atomic weights (Bi) respectively. The presence of bismuth oxide particles ranging in size from 1 to 10 microns is clearly evident on the surfaces of the agglomerates whose MMOA were milled for zero hours. As the duration of MMOA milling increases the bismuth oxide particles reduce in size and become more scattered. These measurements correspond with the largest particle size dimensions observed by laser diffraction analysis of the milled $\mathrm{MMOA}^{10}$. The bismuth oxide particles appear to be the most resistant to being reduced in size during vibratory milling of the MMOA. If the as-received bismuth oxide particles consisted of an alternative morphology, requiring less energy to reduce them to submicron particles, the duration of vibratory milling of the MMOA would be shorter. Less work required by the mill to reduce the size of the MMOA would also result in reduced wear of the $\mathrm{ZrO}_{2}$ media and thus lower $\mathrm{Zr}$ concentrations ${ }^{10}$. 


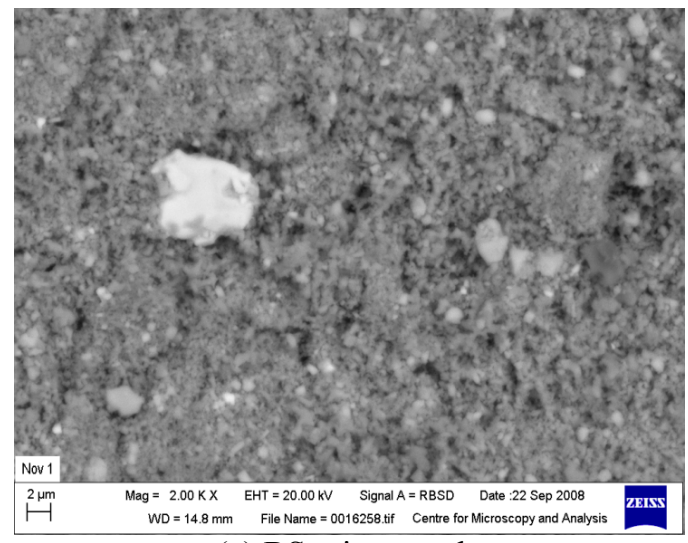

(a) BS micrograph

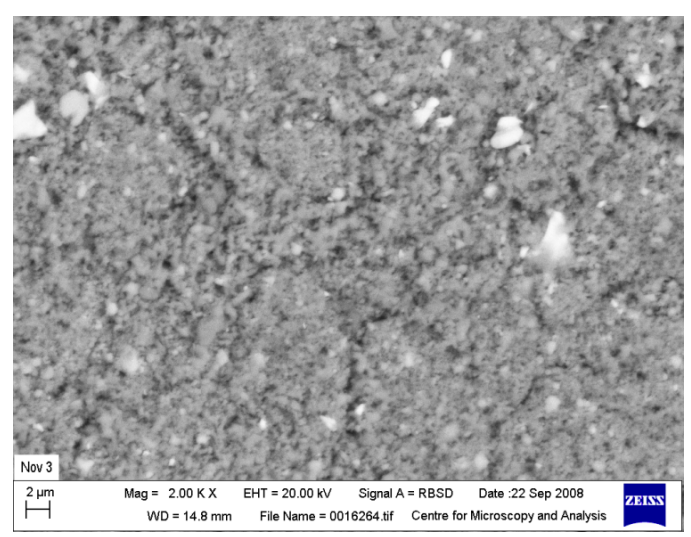

(b) BS micrograph

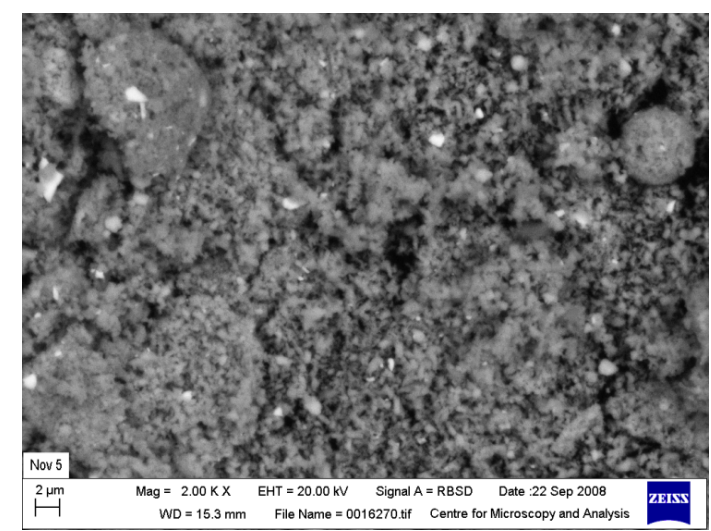

(c) BS micrograph

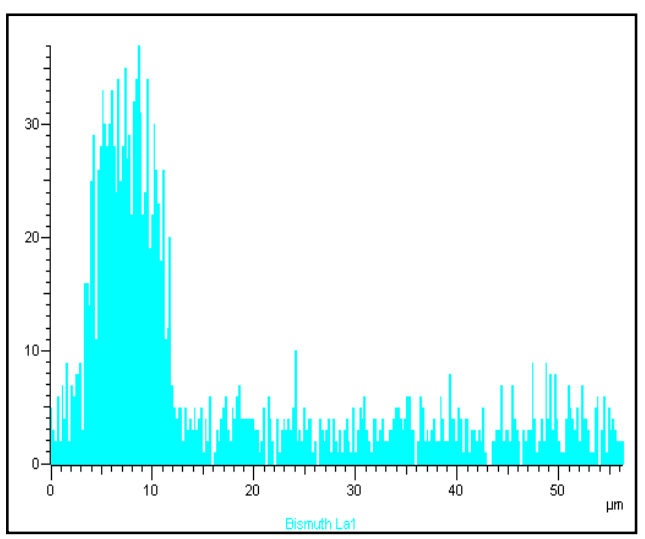

(a) Bismuth line graph

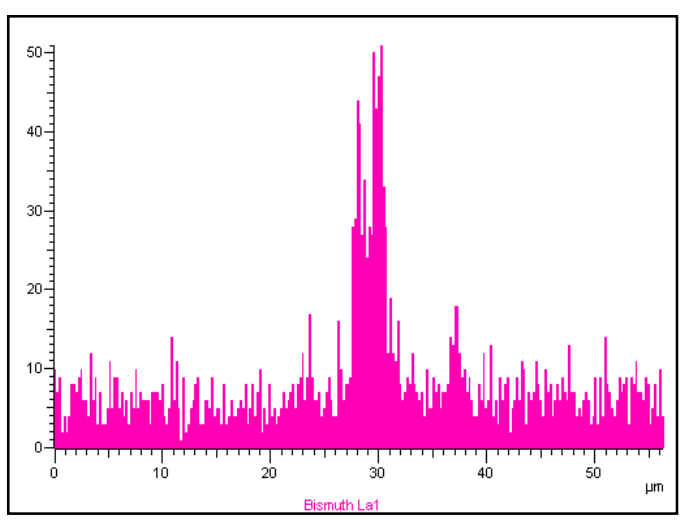

(b) Bismuth line graph

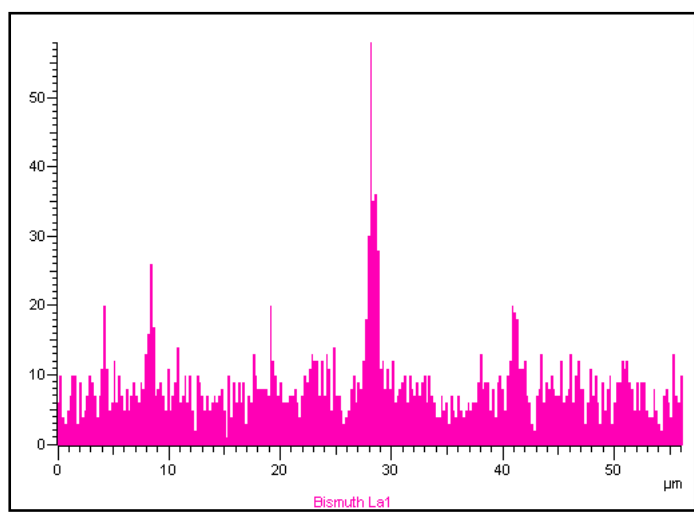

(c) Bismuth line graph

FIGURE 3. Back scattering electron micrographs (BS) and bismuth line graphs of first spray-dried agglomerates from batches in which the MMOA were milled for (a) zero hr, (b) $6 \mathrm{hr}$ and (c) $12 \mathrm{hr}$. 


\section{Characteristics of The Second Milled Powders}

The duration of vibratory milling of the MMOA during the first milling stage had little influence on the particle size (Fig. 4), specific surface area (Fig. 5) and pore size (Fig. 6) of the second milled powders. The concentration of $\mathrm{Zr}$ in the second milled powders was affected by the duration of vibratory milling of the MMOA (Fig. 7).

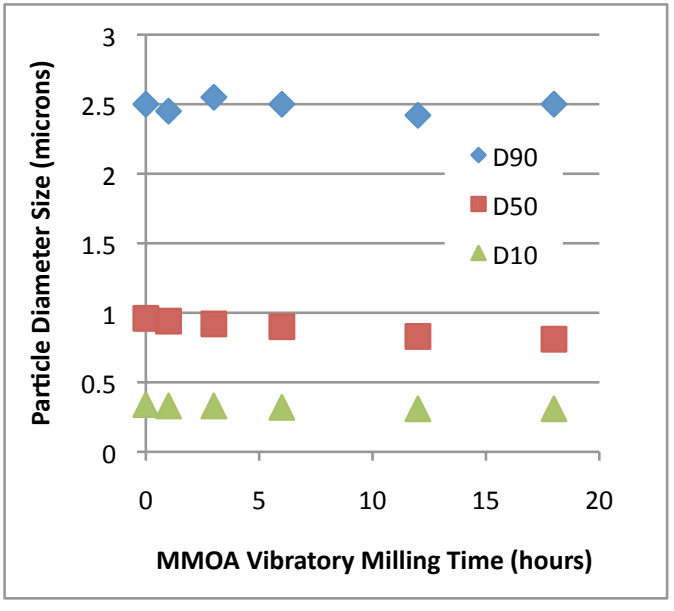

FIGURE 5. Effect of MMOA vibratory milling time on the particle size distribution of the second milled powders.

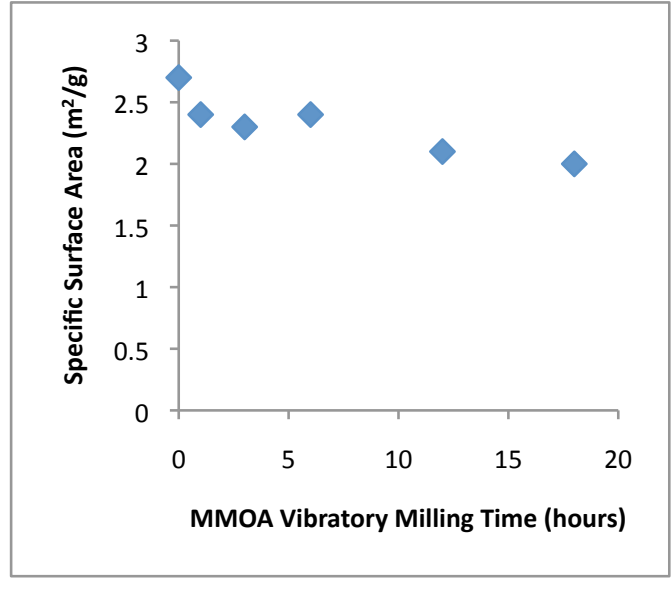

FIGURE 6. Effect of MMOA vibratory milling time on the specific surface area of the second milled powders.

ICP analysis shows that $\mathrm{Zr}$ is present in the second milled powders in the ppm range, 12 to 200. A linear relationship between the duration of MMOA milling and the concentration of $\mathrm{Zr}$ exists. Figure 8 also compares the concentration of $\mathrm{Zr}$ before (calculated from the concentration of $\mathrm{Zr}$ in the $\mathrm{MMOA}^{10}$ combined with $96 \mathrm{~mol}$. \% $\mathrm{ZnO}$ ) and after the second milling stage. The $\mathrm{ZnO}$ powder contained zero ppm $\mathrm{Zr}$.

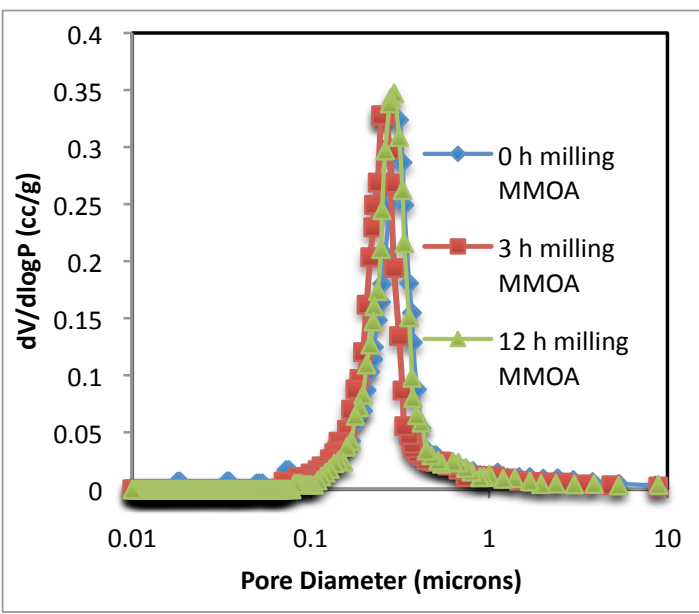

FIGURE 6. Effect of MMOA vibratory milling time on the pore size distribution of the second milled powders.

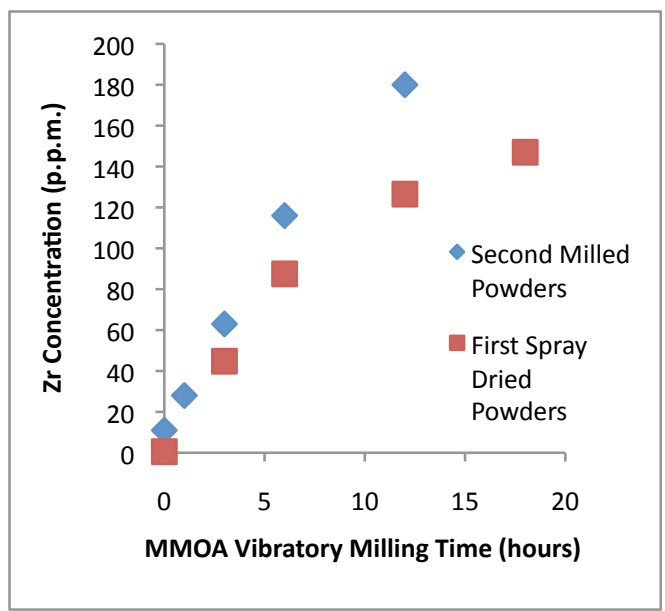

FIGURE 7. Effect of MMOA vibratory milling time on the zirconium concentration of the second milled powders. 
The gain in $\mathrm{Zr}$ concentration indicates that wear of the $\mathrm{ZrO}_{2}$ media occurred during the second milling stage. However, it is much lower than that observed after the first milling stage of the MMOA (5 to $1300 \mathrm{ppm})^{10}$. Most of the $\mathrm{Zr}$ picked up from the media by the varistor powders occurs during the first milling stage. If the concentration of $\mathrm{Zr}$ in the ppm range is important towards varistor behaviour, then control of the media wear during the first milling stage is critical.

Even though all of the calcined varistor powders were milled for 6 hours the gain in $\mathrm{Zr}$ concentration was not equal for all powders and appears to be influenced by the duration of MMOA milling. It increased as the duration of MMOA vibratory milling was increased. The calcined powders made from the MMOA with the smallest particle size and highest $\mathrm{Zr}$ concentration may be more abrasive than those made from MMOA with largest particle size and lowest Zr concentration.

\section{CONCLUSIONS}

Some of the powder characteristics of the first spray drying and second milling stages were influenced by the duration of milling of the MMOA. Most noticeable were the elemental homogeneity within the first spray-dried agglomerates and the concentration of $\mathrm{Zr}$ in the second milled powders. The level of homogeneity of the MMOA, in particular bismuth, within the first spray-dried agglomerates increased with the duration of MMOA vibratory milling. The concentration of $\mathrm{Zr}$ increased further during the second milling stage. The increase in $\mathrm{Zr}$ concentration was less than that observed during the first milling stage and increased with the duration of milling of the MMOA. It is anticipated that the improved homogeneity of the MMOA around the $\mathrm{ZnO}$ particles with increasing vibratory milling duration will result in improved $\mathrm{ZnO}$ grain growth control during sintering and thus better electrical characteristics. The level of $\mathrm{Zr}$ may need to be controlled.

\section{ACKNOWLEDGMENTS}

The authors gratefully acknowledge the support of Littelfuse Ireland Ltd., the CMA unit, Trinity College Dublin and Dr Tim Prescott of Dublin City University.

\section{REFERENCES}

1. F.F. Lange, J. Am. Ceram. Soc., 72, 3-15 (1989).

2. M. Matsuoka, Jpn. J. Appl. Phys., 10, 736-746 (1971).

3. D.R. Clarke, J. Am. Ceram. Soc., 82, 485-502 (1999).

4. T.K. Gupta, J. Am. Ceram. Soc., 73, 1817-1840 (1990).

5. P. Duran, F. Capel, J. Tartaj and C. Moure, J. Am. Ceram. Soc., 84, 1661-1668 (2001).

6. S.C. Pillai, J.M. Kelly, D.E. McCormack and R. Ramesh, Mat. Sci. and Tech., 20, 964-968 (2004).

7. K. Eda, M. Inada, M. Matsuoka, J. Appl. Phys., 54, 1095-1099 (1983).

8. Z. Brankovic, G. Brankovic, S. Bernik and M. Zunic, J. Eur. Ceram. Soc., 27, 1101-1104 (2007).

9. D. McArdle, R. Puyane and M.S.J. Hashmi, 'Effect of comminution process parameters on the electrical energy absorption capability of ZnO varistors,' in AMPT Conference Proceedings - 1995 edited by M.S.J Hashmi, vol. 1, (1995) pp. 557-563.

10. M.C. Kelleher and M.S.J. Hashmi, J. Mat. Proc. Tech., 20, 645-650 (2008). 